\title{
Upstream foraging by medusae
}

\author{
Sean P. Colin ${ }^{1, *}$, John H. Costello ${ }^{2}$, Heather Kordula ${ }^{1}$ \\ ${ }^{1}$ Environmental Sciences, Roger Williams University, 1 Old Ferry Road, Bristol, Rhode Island 02809, USA \\ ${ }^{2}$ Biology Department, Providence College, Providence, Rhode Island 02918, USA
}

\begin{abstract}
Convergence upon similar morphological traits is common among predators feeding on similar prey in similar environments. Aboral placement of tentacles during swimming appears to be such a trait and has evolved in parallel among several medusan lineages. Here we examine this trait in 1 scyphomedusa and 2 hydromedusae representing different lineages within the Medusozoa with the goal of evaluating whether aborally directed tentacles function similarly among these varied medusae. We analyzed flow generation, swimming kinematics and swimming behavior of Craspedacusta sowerbyi (Hydrozoa, Limnomedusa), Nausithoë punctata (Scyphozoa, Coronata) and Solmissus albescens (Hydrozoa, Narcomedusa), and the prey capture mechanics of $N$. puncatata. The 3 species swam similarly and generated similar wake structures in comparison to each other and to oblate medusae with trailing tentacles. Foraging behavior, as measured by the percent of time spent swimming, was similar for medusae possessing both leading and trailing tentacle placement. These findings indicate that medusae possessing either type of tentacle placement swim and forage similarly but that medusae with leading tentacles capture prey 'upstream' while medusae with trailing tentacles capture prey 'downstream' of vortices generated at the bell margin during swimming. These differences in tentacle placement relative to flow around the medusae may have important consequences for prey capture and trophic interactions that lead to different prey-selection patterns.
\end{abstract}

KEY WORDS: Scyphomedusa · Hydromedusa - Evolution · Morphology · Swimming · Feeding · Behavior

Resale or republication not permitted without written consent of the publisher

\section{INTRODUCTION}

The broad morphological and functional diversity observed among medusan species has enabled them to occupy an extensive number of trophic roles. In coastal ecosystems, large conspicuous species are often important predators that are able to structure pelagic foodwebs (Purcell 1989, Matsakis \& Conover 1991). However, there are many less conspicuous or inaccessible medusae whose feeding ecology and trophic roles remain unknown. An examination of the function of different medusan forms may provide a better understanding of medusan trophic diversity and permit insight into the ecological impact of a range of medusan morphologies. This is important because many species are difficult either to obtain or to examine under conditions that are required for detailed knowledge about their feeding habits.
The functional role of bell morphology has been well established for many medusae. Medusan bell shape has been shown to relate to swimming performance, propulsive mode, foraging behavior and even prey selection. Medusae that possess flat or oblate bells (low fineness ratios) typically create large trailing vortex ring structures when they pulse through the water (Ford et al. 1997, Dabiri et al. 2005); their mode of propulsion has been termed rowing (Colin \& Costello 2002). Rowing is effective at entraining large volumes of fluid in the wake of the medusa but is not effective at accelerating the medusa rapidly. Consequently, oblate medusae exhibit lower swimming performance relative to medusae with more bullet or prolate shapes (Colin \& Costello 1996, 2002) but are able to use the large volume of fluid that is entrained for drawing prey into capture surfaces. Therefore, oblate medusae generally forage while swimming as cruising predators 
(Costello \& Colin 1994, Colin et al. 2003). Medusae that possess more prolate bell forms (high fineness ratios) generally expel a jet of fluid from within their bell cavity during pulsation and this mode of propulsion has been aptly termed jetting (Daniel 1983). Jet propulsion is effective at accelerating the medusa rapidly but is thought to be energetically expensive (Daniel 1983). Therefore, while jet-propelled medusae can typically accelerate more rapidly to higher velocities than oblate forms, they spend only a small fraction of their time swimming (Colin et al. 2003). Instead, they typically spend the majority of time relatively motionless with tentacles extended in an ambush foraging mode. The different foraging modes result in different prey selection patterns such that, given similar prey availability, oblate medusae select non-motile and slow swimming prey (e.g. fish larvae and eggs; Greene 1986, Purcell \& Mills 1988, Sullivan et al. 1994, Costello \& Colin 2002) and prolate medusae select more rapidly swimming prey (e.g. copepods; Greene 1986, Purcell \& Nemazie 1992, Costello \& Colin 2002).

Tentacles are also thought to be important for determining prey selection (Madin 1988, Purcell 1997). However, the role of tentacle morphology (e.g. placement, number and thickness) in prey selection has not been as well established as that of bell shape. In this study, we examined a group of medusae that place their tentacles aborally (Fig. 1). Three medusan orders (classification scheme from Marques \& Collins 2004), 1 scyphomedusan (order Coronatae) and 2 hydromedusan (orders Limnomedusae and Narcomedusae), contain species that place their tentacles aborally (Fig. 2). Possession of aborally positioned tentacles within these lineages is interesting since medusae from their sister lineages are not characterized by aborally positioned tentacles yet are believed to share common anscestors (Collins 2001, Marques \& Collins 2004). Homoplasy, or in the preferred term of Willmer (2003), convergence, of aboral tentacle placement within these medusan lineages represents a functional solution that may be the most widespread type of medusan predatory mode in the mid and deep regions

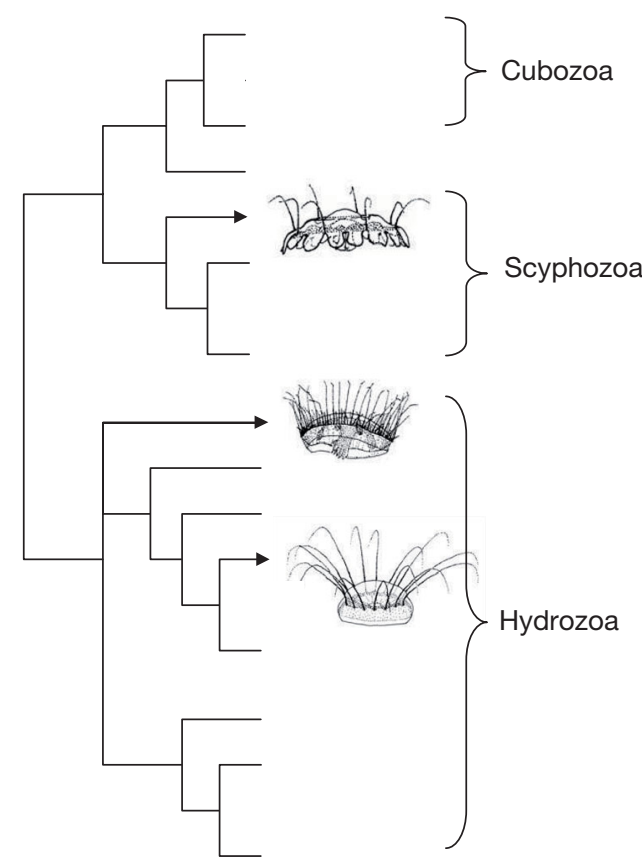

Fig. 2. Cladistic relationship of medusazoa based on cladistic analysis of Marques \& Collins (2004). Arrows pointing to (from top to bottom) Nausithoë punctata, Craspedacusta sowerbyi, Solmissus albescens indicate the location of Coronates, Limnomedusae and Narcomdusae, respectively. The brackets indicate which clades represent Scyphomedusae and Hydromedusae

of the world's oceans (Raskoff 2002). However, it is not presently clear whether medusae with aboral tentacle placement function similarly from either a propulsive or foraging perspective. Does possession of this similar form imply similar function?

We address this issue by quantitatively examining the swimming performance, propulsive mode and foraging behavior of 3 species of medusae with aborally directed tentacles, Nausithoë punctata (Scyphozoa, Coronatae), Craspedacusta sowerbyi (Hydrozoa, Limnomedusae) and Solmissus albescens (Hydrozoa, Narcomedusae). Our intention is to evaluate the functional attributes of foraging by these medusae and place
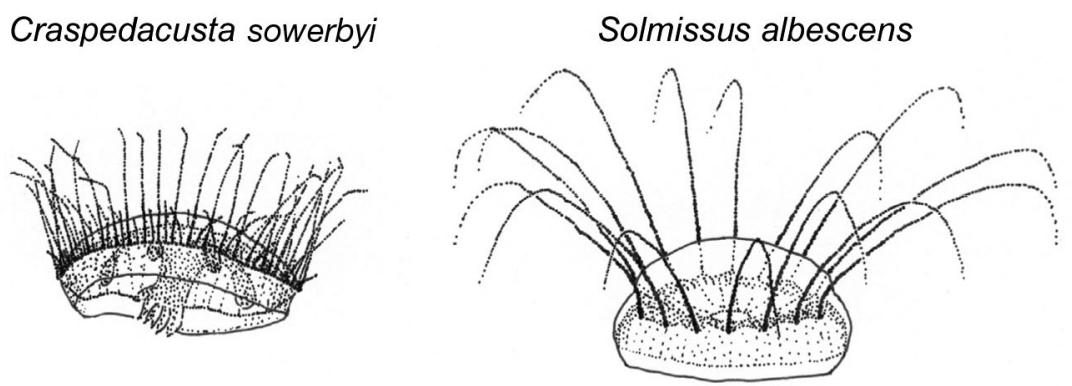

\section{Nausithoë punctata}

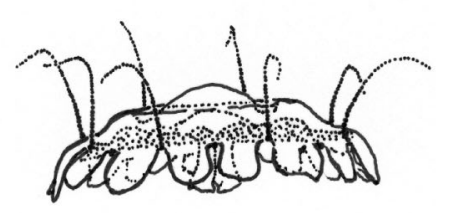

Fig. 1. Craspedacusta sowerbyi, Solmissus albescens and Nausithoë punctata. Medusan species examined in this study shown in their foraging posture with tentacles aborally positioned. Medusae diameters $(\mathrm{cm})=$ C. sowerbyi 1.5, S. albescens 5.0, N. punctata 1.0 
them within the larger context of alternative foraging modes found within sister lineages possessing medusae.

\section{MATERIALS AND METHODS}

In order to examine the morphology, swimming and foraging of each of the species studied (Craspedacusta sowerbyi, Nausithoë punctata and Solmissus albescens), we (1) observed the flow around the medusae during swimming (Dabiri et al. 2005), (2) measured their bell shapes, velar aperture ratios and kinematic profiles (Colin \& Costello 2002), and (3) quantified the percent of the time medusae spent swimming and their tentacle extension during swimming (Colin et al. 2003). Each species was examined independently depending on our access to the medusae. We followed the methods described in the studies above with some variations depending on the medusae and working conditions which are detailed below.

Craspedacusta sowerbyi. Craspedacusta sowerbyi (0.5 to $1.5 \mathrm{~cm}$ diameter), a freshwater limnomedusa, were hand-collected in jars from a freshwater pond in Lincoln, Rhode Island, USA during August 1995 and immediately transported to the laboratory. In the laboratory individuals were placed into 21 filming vessels filled with ambient freshwater at ambient temperatures $\left(20^{\circ} \mathrm{C}\right)$. Artemia sp. cysts and nauplii were also added to the vessels as particles for tracking flow and as prey. The swimming and foraging behaviors of C. sowerbyi individuals were videotaped within $48 \mathrm{~h}$ of collection.

Video recordings were made according to the methods of Costello \& Colin (1994). Accordingly, medusan foraging, swimming and particle flow were recorded using a backlit optical system. Video fields were labeled with a field counter to provide temporal data and spatial characteristics of the optical field were determined from scale bars periodically included in the original recordings.

Morphological and kinematic measurements were made directly from the video recordings and calibrated with the scale bars. Calculations made from the measurements followed the methods of Colin \& Costello (2002). Specifically, changes in bell shape were quantified by the fineness ratio, $F$ :

$$
F=h / d
$$

where $h$ is bell height and $d$ is bell diameter. $F$ was used to determine variations in bell morphology throughout the pulsation cycle of the medusae. Hence, a minimum $F$ corresponds to the fully expanded bell (i.e. bell at rest) and a maximum $F$ corresponds to a fully contracted bell.
We also measured the velar aperture area ratio which compares the relative area of the velar aperture to the total area determined by the bell diameter when the bell is at rest (i.e. fully expanded). This ratio has been used to determine how the medusan morphology is designed to constrict the opening through which water is expelled from the subumbrellar volume during bell contraction. Oblate rowing medusae have been found to minimize this constriction (i.e. maximize velar aperture area ratio), while prolate jetting medusae maximize this constriction (i.e. minimize velar aperture area ratio; Colin \& Costello 2002). Measurements were made from medusae at rest because of the difficulty of imaging the velum during bell contraction. The bell diameter $(d)$ and the diameter of the velar aperture $(v)$ were measured from each of the medusae videotaped. Assuming that the velar aperture and bell were circular in cross-section, the ratio of their areas, the velar aperture area ratio, $\mathrm{R}_{\mathrm{v}}$, can be simplified to $\mathrm{a}$ percentage based on the relationship:

$$
\mathrm{R}_{\mathrm{v}}=v^{2} / d^{2}
$$

The kinematic profiles were measured from 3 different medusae swimming for 3 to 5 consecutive bell pulsations (Colin \& Costello 2002). The distance $(D)$ that the medusae traveled over time was measured from sequential changes in position $(x, y)$ of the anteriormost point of the exumbrellar surface over 0.05 to $0.08 \mathrm{~s}$ intervals $(t)$. The subscript $i$ in the equation is used to denote instantaneous measurements. Motion only within the 2-dimensional viewing field was ensured by using a sequence in which bell orientation remained level throughout the sequence.

The velocity $(u)$ at Time $i$ was calculated over the Time Interval $t$ as an average:

$$
u_{i}=\frac{D_{i+1}-D_{i-1}}{2 t}
$$

And the instantaneous acceleration $\left(\mathrm{A}_{i}\right)$ was calculated as:

$$
\mathrm{A}_{i}=\frac{D_{i+1}+D_{i-1}-2 D_{i}}{t^{2}}
$$

Statistical analysis utilized analysis of variance (ANOVA) tests. Individual comparisons between species were based on the Tukey-Kramer post-hoc test.

We followed the methods of Colin \& Costello (2002) to track particles in the fluid surrounding the bell in order to visualize the fluid motions surrounding Craspedacusta sowerbyi. The particles used for tracking were cysts and newly hatched Artemia sp. that were placed in the vessel with the medusae. We traced particle tracks by hand during 2 periods of the bell contraction, 3 fields prior to maximum bell contraction (which corresponds to the period of maximum medu- 
san acceleration) and 3 fields prior to maximum expansion. Flow-field images were taken only when the camera was still and the medusae traveled through the field of view. The flow-field was constructed from several pulsation cycles of one medusa because no single cycle contained enough particles with the appropriate location and trajectory. We used only particles that remained in focus the entire $0.1 \mathrm{~s}$ duration to minimize error by ensuring the particle was only moving in 2 dimensions. We measured the flow field by superimposing an $x, y$ grid on a video sequence of the free swimming medusa. Since the medusa's position changed as it swam, the grid was positioned relative to the medusa's bell. Therefore, all the particle velocities were measured with respect to the medusa's bell. The path and distance the particles traveled were traced over 3 consecutive fields $(t=0.1 \mathrm{~s})$. Particle velocities were determined based upon the distance traveled over an $0.1 \mathrm{~s}$ interval.

Solmissus albescens. All observations of Solmissus albescens (2 to $5 \mathrm{~cm}$ diameter), an oceanic narcomedusa, were made during a research cruise to the Southern Adriatic during June 2002 and July 2003. We initially collected the medusae by hand and attempted to work with them in the laboratory using the methods described above; however, they would not swim or forage in the filming vessels. Therefore, all observations of $S$. albescens were made using in situ video taken by SCUBA divers. This turned out to be beneficial since in situ video has several advantages over laboratory observations for flow measurements (Dabiri et al. 2005). These include facilitating the use of fluorescent dye to visualize the flow surrounding the medusae and eliminating the need for an imposed flow current (as is necessary in a laboratory kriesel tank). Further, the swimming kinematics and foraging behavior measured by this method should be more relevant to the behavior of the medusae in nature compared to those achieved by any type of laboratory tank.

Solmissus albescens is an offshore oligotrophic species that migrates to depth during the day and sometimes approaches the surface at night. Therefore, the dives were made around midnight at 15 to $25 \mathrm{~m}$ depth in areas of the Adriatic that are approximately $1300 \mathrm{~m}$ deep (Benović et al. 2000). In situ video followed the methods of Dabiri et al. (2005), except that natural lighting was not used. Instead, lighting was provided by high intensity discharge lights (Light \& Motion) attached to a video (Sony DCR VX2000 camera) housing (Amphibico). S. albescens is a vertically migrating species that avoids light (Mills \& Goy 1988) and prolonged exposure to lights during video sessions resulted in behavior alterations. All medusae were initially observed with their tentacles positioned aborally. However, after several minutes of exposure,
S. albescens moved their tentacles downward to a more trailing position and swam rapidly away from the lights. In order to avoid the behavioral artifact introduced by lighting, we utilized video only from individuals with their tentacles positions aborally in their initial predatory stance. Morphological and kinematic analysis followed the methods described above for Craspedacusta sowerbyi except that extra care was taken in selecting sequences to be analyzed since the video camera and the medusa were not fixed as in the laboratory. To ensure that the distance between the camera and the medusa remained constant throughout the swimming sequences analyzed, we only used swimming sequences where the size of the medusa did not change on the viewing screen throughout the sequence. Changes in medusan position were made relative to non-entrained particles (assumed to represent the ambient fluid) in the background of the swimming medusae.

Flow visualization was accomplished using fluorescent dye (Dabiri et al. 2005). To achieve these video sequences, a second diver injected $10 \mu \mathrm{l}$ pulses of concentrated fluorescent dye into the fluid at specific locations around the medusa. This second diver was located to the side of the medusa at $90^{\circ}$ to the orientation of the video camera. Both divers took care to avoid disturbing the fluid around the medusa being videotaped. Fluid disturbances created by the divers were made obvious by the dye and these shots were excluded from the video analysis. The length of the pipette used to administer the dye was used as a calibrating size scale in later analysis.

Nausithoë punctata. Nausithoë punctata (0.4 to $1 \mathrm{~cm}$ diameter), a small coronate scyphomedusae, was hand-collected by SCUBA divers from a marine lake (145 ha, maximum depth $46 \mathrm{~m}$ ) on the island of Mljet, Croatia, in the Adriatic Sea $\left(42.75^{\circ} \mathrm{N}\right.$, $17.55^{\circ} \mathrm{E}$ ) during July 2003 and immediately transported to a laboratory adjacent to the lake. In the laboratory, individuals were placed into $100 \mathrm{ml}$ filming vessels with ambient seawater at ambient temperatures $\left(18^{\circ} \mathrm{C}\right)$. Natural plankton, collected using a $200 \mu \mathrm{m}$ mesh plankton net, were added to the vessels as prey. Video recordings and morphological and kinematic analyses followed the methods described above for Craspedacusta sowerbyi. Because scyphomedusae do not possess a velum, the aperture opening is determined solely by the bell diameter. Therefore, we assumed $\mathrm{R}_{\mathrm{v}}$ to equal $100 \%$ of $N$. punctata's bell diameter.

Flow visualization around swimming Nausithoë punctata utilized fluorescent dye. A syringe was used to inject thin lines of dye into the filming vessel in the path of the swimming medusae in order to visualize the medusae swimming through the dye. 
While there exists a relatively substantial body of feeding data for both Craspedacusta sowerbyi and Solmissus albescens, little data exists for Nausithoë punctata. Therefore, we measured the capture efficiency of medusae fed natural prey assemblages. To do this, medusae were placed in dishes with concentrated natural prey assemblages and videotaped for $20 \mathrm{~min}$ intervals using a Pulnix camera attached to a stereomicroscope. Prey were collected using a $150 \mu \mathrm{m}$ mesh net and concentrated to 10 times their natural concentration. This was done to increase the number of encounters that occurred in $20 \mathrm{~min}$ because prey concentrations are low in the oligotrophic waters of the Southern Adriatic Sea. These concentrations did not appear to affect prey escape behaviors. The prey assemblage was dominated by copepods, small hydromedusae (Aglaura hemistoma, Rhopalonema sp. and singlenectophore siphonophores) and acantharians. Capture efficiencies were measured according to Colin et al. (2005), where capture efficiency $=$ number of captures/number of encounters. An encounter was defined as a contact between prey and predator or an escape reaction of the prey before contact occurred. A capture was defined as a transfer of prey to the oral arm of the medusa. In addition, the surface of contact was noted in order to determine primary capture surfaces. While the analysis of capture efficiencies is not a measure of prey selection it provides important information on the mechanisms of prey capture that are important for understanding prey selection patterns.

\section{RESULTS}

\section{Morphology and flow}

Craspedacusta sowerbyi, Solmissus albescens and Nausithoë punctata vary in size but are morphologically similar in their aboral tentacle positioning (Fig. 1), oblate bell shapes (fineness ratios $\leq 0.4$ ) and large velar aperture ratios (>74\%) (Table 1$)$. While the 3 medusae all possess oblate bells, the bells of $C$. sowerbyi and $N$. punctata are much flatter than that of $S$. albescens and possess average fineness ratios of 0.21 and 0.19 versus 0.40, respectively (Table 1). Despite these minor differences in fineness, the flow visualizations using fluorescent dye revealed that $S$. albescens and $N$. punctata produce qualitatively similar wake structures. Specifically, they generate 2 distinct vortex rings during different phases of the swimming cycle that are of opposite rotation and at separate locations relative to the bell. During the contraction phase of the swimming cycle, the medusae generated a starting vortex ring (Fig. 3A,C). The starting vortex ring consisted of fluid that came from both inside the subumbrellar volume and outside the bell via entrainment of surrounding fluid. By the end of the contraction phase, the starting vortex ring was fully developed and traveling away from the medusae.

As the bell expanded during the relaxation phase of the swimming cycle, a large stopping vortex ring was observed to be formed inside the subumbrellar cavity of both species (Fig. 3B,D). This vortex ring possessed a rotation opposite to the starting vortex ring. The stopping vortex ring consisted of fluid that came from outside the bell and was drawn into the subumbrellar cavity during bell expansion. During bell contraction, a portion of the stopping vortex ring was ejected from the bell and co-joined with the starting vortex ring. The subsequent wake structure, termed the lateral vortex superstructure (Dabiri et al. 2005), traveled downstream from the medusae. In the wake, the sequential trailing vortex superstructures were closely spaced with separation of approximately 1.2 and 1.4 ring radii for Solmissus albescens and Nausithoë punctata, respectively.

For Craspedacusta sowerbyi, particle tracks were used to visualize the flow around the medusa. The particle paths revealed a large starting vortex ring during the contraction phase of swimming (Fig. 4A). While the bell interfered with the visualization of the full stopping vortex ring inside the bell, the particle tracks showed that particles were drawn into the stopping vortex ring during expansion (Fig. 4B). In addition to vortices, the particle paths enabled us to estimate how far the medusae accelerated particles located along the aboral surface of the bell. The region beyond the particle paths in Fig. 4 indicates where particle motion was

Table 1. Craspedacusta sowerbyi, Solmissus albescens and Nausithoë punctata. Summary of morphological and kinematic traits. Morphological traits are averages $( \pm$ SD) of 3 medusae, each at rest. Kinematic data are averages $( \pm$ SD) of 3 medusae, and at least 3 pulses were averaged for each individual. $\mathrm{F}_{i}$ and $\mathrm{R}_{\mathrm{v}}$ : fineness ratio and aperture velar ratio, respectively

\begin{tabular}{|lcccccc|}
\hline Species & $\begin{array}{c}\text { Diameter } \\
(\mathrm{cm})\end{array}$ & $\mathrm{F}_{i}$ & $\begin{array}{c}\mathrm{R}_{\mathrm{v}} \\
(\%)\end{array}$ & $\begin{array}{c}\text { Contraction } \\
\text { time }(\mathrm{s})\end{array}$ & $\begin{array}{c}\text { Peak } \\
\text { velocity }\left(\mathrm{cm} \mathrm{s}^{-1}\right)\end{array}$ & $\begin{array}{c}\text { Peak } \\
\text { acceleration }\left(\mathrm{cm} \mathrm{s}^{-2}\right)\end{array}$ \\
\hline C. sowerbyi & $1.18(0.11)$ & $0.21(0.03)$ & $91.27(2.95)$ & $0.16(0.04)$ & $3.22(1.00)$ & $31.12(13.32)$ \\
S. albescens & $4.08(0.71)$ & $0.40(0.03)$ & $74.39(0.79)$ & $0.19(0.06)$ & $4.77(0.31)$ & $32.48(5.55)$ \\
N. punctata & $0.56(0.05)$ & $0.19(0.05)$ & $100(0)$ & $0.13(0.01)$ & $1.98(0.56)$ & $25.50(10.31)$ \\
\hline
\end{tabular}



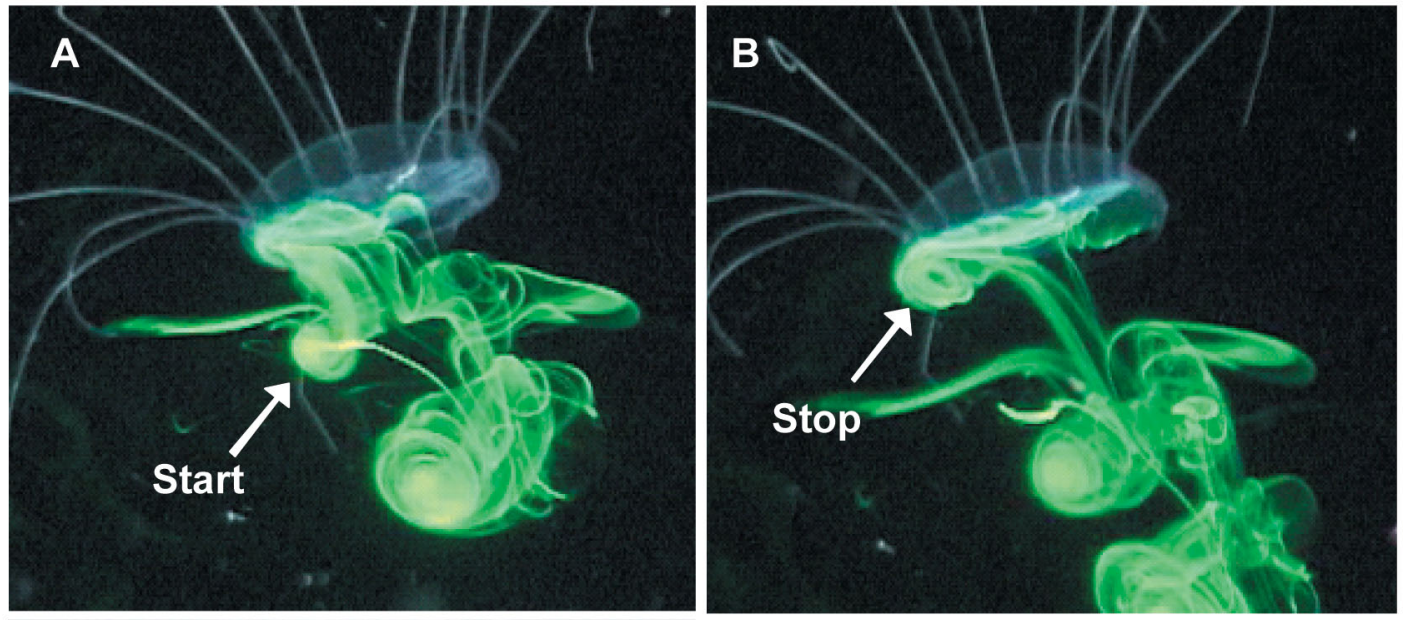

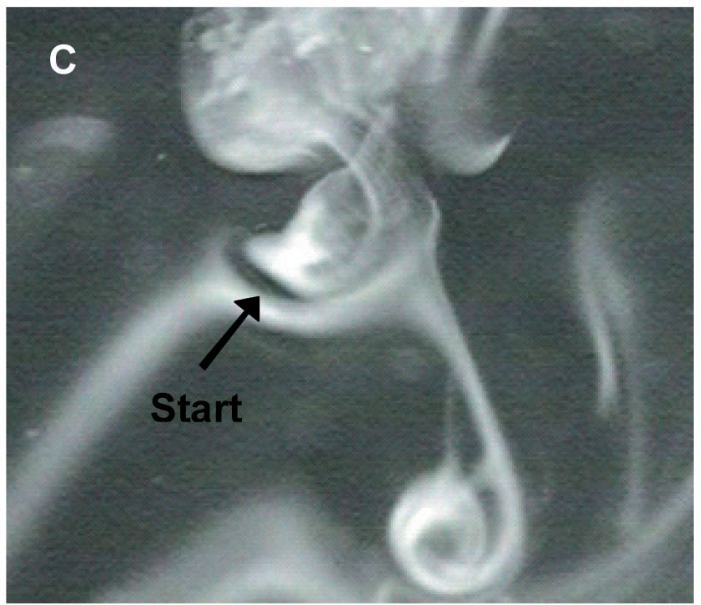

Contraction

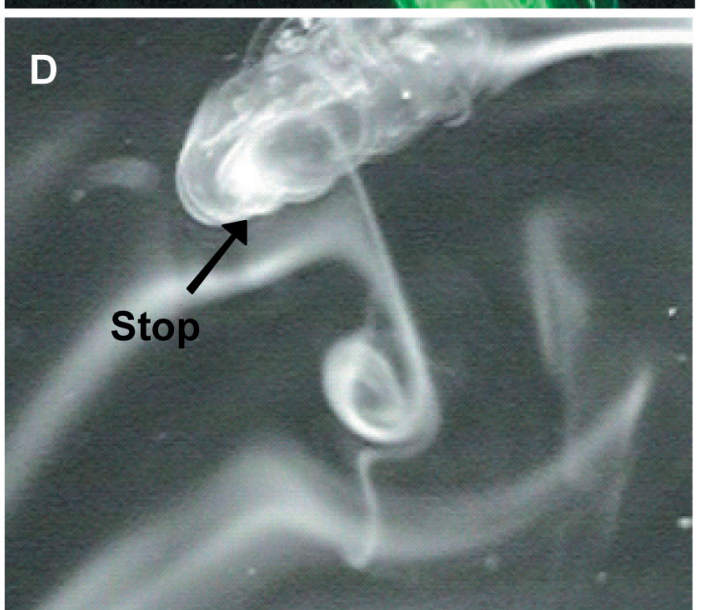

Relaxation

Fig. 3. Solmissus albescens and Nausithoë punctata. Flow generated by (A, B) Solmissus albescens and (C,D) Nausithoë punctata during contraction (left-hand photos) and relaxation (right-hand photos) phases of the swimming cycle. Arrows point to the starting vortices in left-hand and to stopping vortices in right-hand photos

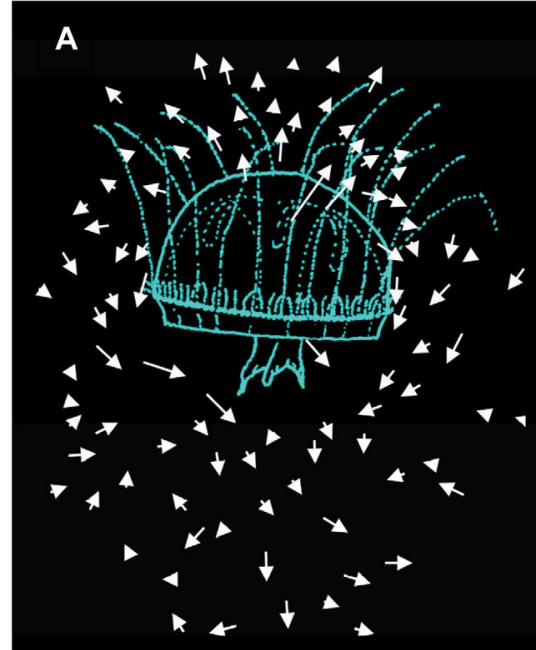

Contraction

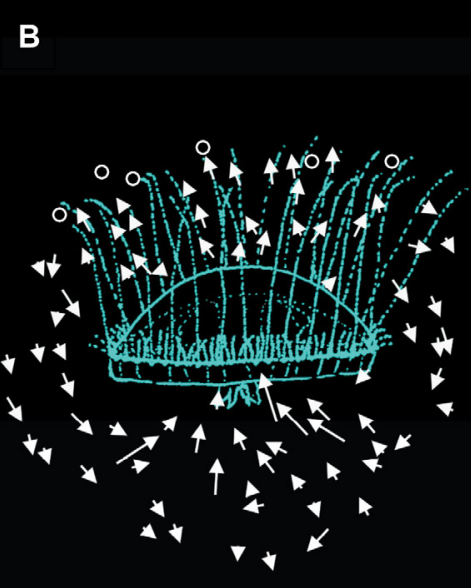

Relaxation
Fig. 4. Craspedacusta sowerbyi. Particle tracks in the flow surrounding medusa during contraction (left) and relaxation (right) phases of the swimming cycle. Only particles where motion was detected were quantified. No flow was detected above the arrows (aboral to the bell). Arrows: distance particles travelled over $0.1 \mathrm{~s}$. Circles: particles that did not move over tracked duration. Diameter of relaxed medusa bell is $1.5 \mathrm{~cm}$ 
undetectable. During both the contraction and relaxation phases, the tentacles of $C$. sowerbyi extended into the regions without particle motion.

\section{Swimming kinematics and behavior}

The bells of Craspedacusta sowerbyi, Solmissus albescens and Nausithoë punctata contracted and relaxed rhythmically and were quantified by changes in the fineness ratio (Fig. 5A-C). Bell pulsation resulted in positional changes during medusan swimming (Fig. 5J-L). For all 3 species, maximum acceleration and velocity values immediately preceded maximum bell contraction. The medusae decelerated as their bells expanded during bell relaxation (Fig. 5D-I).

Kinematic characteristics (contraction times, peak accelerations and velocities) of each pulsation cycle by Craspedacusta sowerbyi, Solmissus albescens and
Nausithoë punctata were averaged for individual kinematic profiles and 3 individuals were averaged for each species (Table 1). While the contraction times and accelerations did not vary significantly between species (1-way ANOVA, p > 0.2), $S$. albescens reached higher peak velocities than $N$. punctata (TukeyKramer post hoc test, $\mathrm{p}<0.05$ ). This is probably due to the substantially larger size of $S$. albescens. However, despite their statistical differences, the accelerations and velocities reached by the different species were of a similar magnitude (Fig. 5)

Medusan foraging strategies are closely linked to the amount of time individuals spend swimming vs. resting (Colin et al. 2003). Therefore, we measured the amount of time each species spent swimming in our video sequences. The 3 species examined were found to spend a majority of their time (>70\%) swimming, and always extended their tentacles during swimming (Table 2).
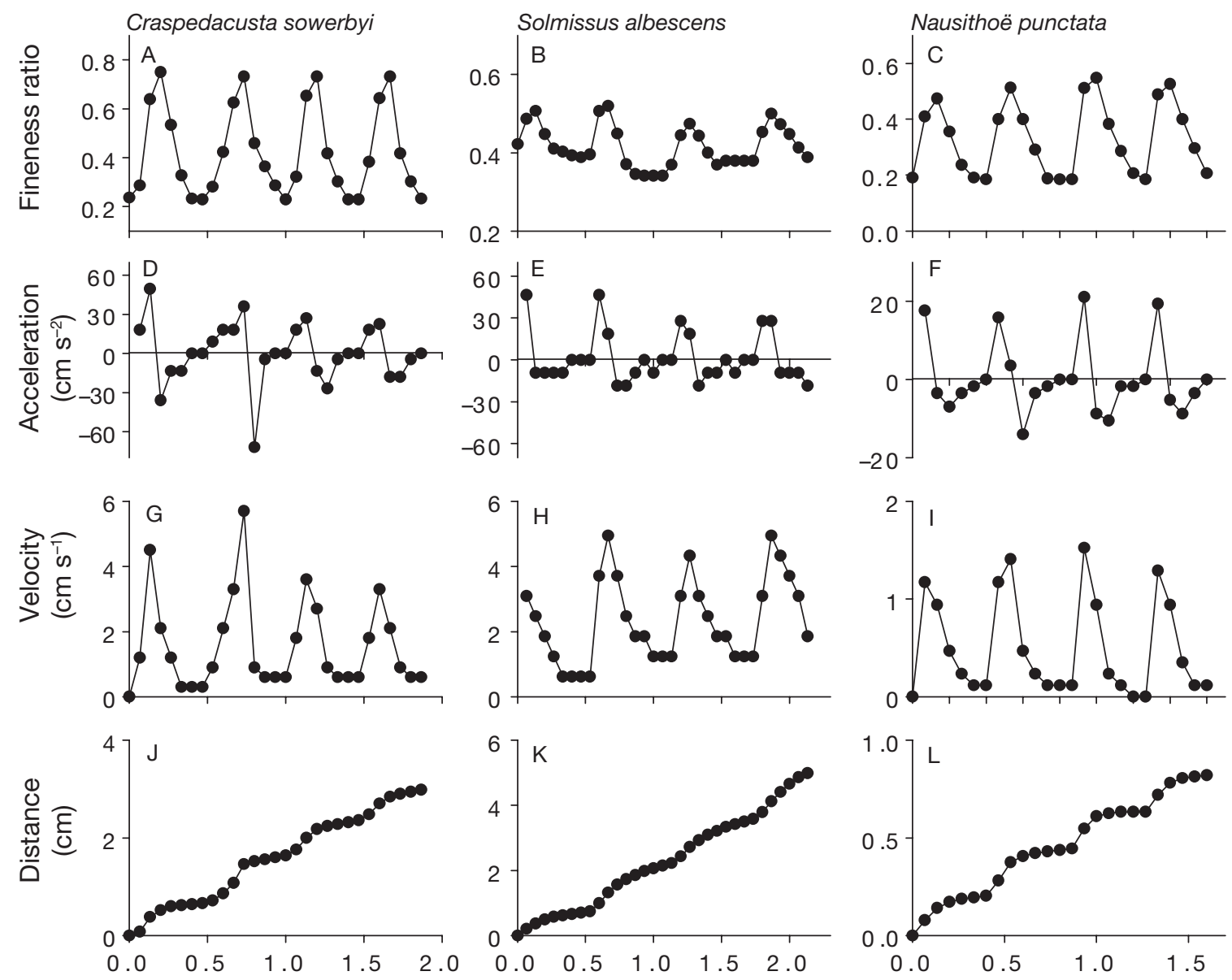

Time (s)

Fig. 5. Craspedacusta sowerbyi, Solmissus albescens and Nausithoë punctata. Representative kinematic profiles. Note differences in $x$ and $y$ scales 
Table 2. Craspedacusta sowerbyi, Solmissus albescens and Nausithoë punctata. Average $( \pm \mathrm{SD})$ percent of time each species spent swimming. n: no. of medusae

\begin{tabular}{|lrcc|}
\hline Species & $\mathrm{n}$ & $\begin{array}{c}\text { Total time } \\
\text { (min:s) }\end{array}$ & $\begin{array}{c}\text { Time spent } \\
\text { swimming (\%) }\end{array}$ \\
\hline C. sowerbyi & 4 & $25: 34$ & $70.7(17.0)$ \\
S. albescens & 39 & $39: 47$ & $93.5(20.7)$ \\
N. punctata & 3 & $44: 23$ & $79.5(14.2)$ \\
\hline
\end{tabular}

\section{Nausithoë punctata prey retention}

Encounters between Nausithoë punctata and prey were initiated either by $N$. punctata swimming into a resting prey item or by a highly motile prey (e.g. copepod or siphonophore) jumping into the medusa's bell or tentacle. $N$. punctata rarely reacted to contacts with acantharians or dinoflagellates. These prey items generally bounced off the tentacles of $N$. punctata without being captured. Consequently, N. punctata exhibited low capture efficiencies for these prey types (Fig. 6A). When $N$. punctata medusae came into contact with

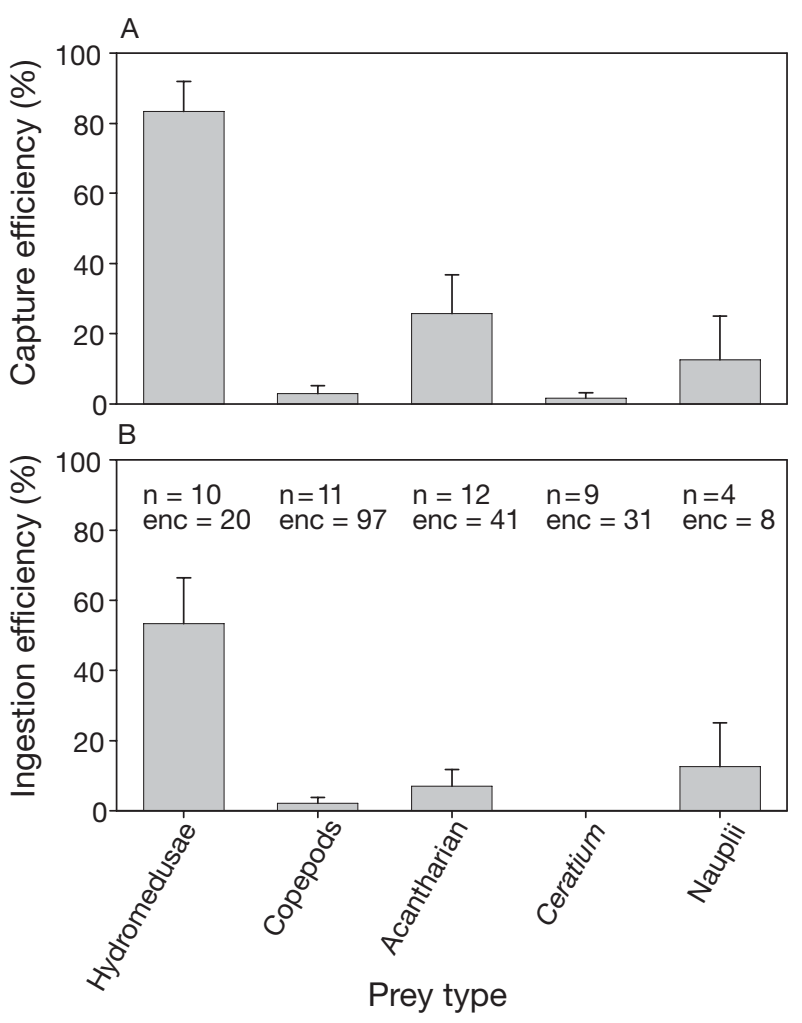

Fig. 6. Nausithoë punctata. (A) Capture efficiencies (no. captured/no. encountered) and (B) ingestion efficiencies (no. ingested/no. encountered) on different types of prey. n: number of medusae examined; enc: total number of encounters analyzed. Error bars: +SD small hydromedusae, copepods or copepod nauplii, the $N$. punctata medusae rapidly swung their tentacles from an aboral position around the bell margin to the mouth. This occurred without the rigid tentacle contracting or changing length. The number of tentacles that moved toward the mouth depended upon the number of tentacles that were contacted by prey. Similar observations of Nausithoë sp. feeding behavior were made by Larson (1979). N. punctata was significantly more efficient at capturing ( $\mathrm{p}<0.02$; Kolmogorov-Smirnov non-parametric test for unpaired comparisons; see Fig. 6 for information on the number of medusae used in the analyses) and ingesting ( $p<0.03)$ small hydromedusae (including single-nectophore siphonophores and the hydromedusae Rhopalonema sp. and Aglaura hemistoma) than all other prey types (Fig. 6A). Small hydromedusae, copepods and nauplii that were encountered but not ingested either escaped before capture or were captured momentarily before escaping during transfer to the mouth. Only copepods (14\% of encounters) and nauplii (13\%) were able to detect an approaching medusa and escape before contacting the bell or tentacle. However, N. punctata was able to contact most copepods and nauplii in its path before detection (86 and $87 \%$, respectively).

\section{DISCUSSION}

As a basal metazoan group, cnidaria possess a simple animal body plan constructed from only a limited number of cell types (generally less than 10 types; Valentine 2004). Despite their simplicity, medusae have evolved numerous design variations of their bells, tentacles and manubriums (or oral arms). The diversity in these body parts affects their feeding and, hence, trophic roles in aquatic ecosystems. Craspedacusta sowerbyi, Solmissus albescens and Nausithoë punctata are 3 species that are conspicuously alike in their aborally positioned tentacles. We have demonstrated that they are also morphologically similar in their oblate bell forms (i.e. fineness ratios less than 0.5) and their large velar apertures (Table 1). In fact, this bell form is common for species with aboral tentacles. The average bell fineness calculated from a survey of the medusan species with aborally positioned tentacles is 0.52 with a median of $0.43(n=18$ coronate species and $n=34$ narcomedusan species; Mayer 1910).

Bell fineness and velar aperture size are important morphological characteristics that influence medusan propulsion, kinematics and foraging strategies (Colin \& Costello 2002, Costello \& Colin 2002, Raskoff 2002, Colin et al. 2003). The similarities in these traits for Craspedacusta sowerbyi, Solmissus albescens and Nausithoë punctata suggest that they function simi- 
larly, i.e. as rowing, cruising predators. We argue that medusae with aboral tentacles function similarly to oblate medusae with trailing tentacles but differ in the region of the ambient flow into which the medusae position their tentacles and, therefore, capture prey (Fig. 7).

\section{Morphological and swimming interactions}

Bell morphology is directly linked to propulsion because bell shape and velar aperture ratio affect how a medusa interacts with the surrounding fluid during bell contraction. A detailed study of the wake formation by the oblate scyphomedusa Aurelia aurita found that $A$. aurita created starting and stopping vortices during their bell contraction and relaxation, respectively, which co-joined during the contraction phase to form large trailing vortex superstructures in their wake (Dabiri et al. 2005). This wake structure, which forms during rowing propulsion (Dabiri et al. 2005), is considerably more complex than the wake of a simple jet (Weihs 1977) and indicates that $A$. aurita uses a mode of propulsion that is different from the traditional model of jet propulsion. We observed wake structures for Craspedacusta sowerbyi, Solmissus albescens and Nausithoë punctata that were similar to those of A. au- rita (Figs. 3 \& 4). Dye visualizations revealed that $S$. albescens and $N$. punctata created large starting and stopping vortex rings with trailing vortices separated by less than 1.5 ring radii. The presence of a stopping vortex and closely spaced vortex ring separation are characteristic of rowing propulsion (Ford et al. 1997, Dabiri et al. 2005) rather than traditional jet propulsion (Weihs 1977, Daniel 1983). Dynamical fluid similarities among rowing medusan species are expected since these medusae possess similar low fineness ratios and large velar apertures. While we do not have dye video for C. sowerbyi, the similar bell fineness, velar aperture and the large trailing vortices documented by particle tracks suggest that $C$. sowerbyi interacts with surrounding fluid and uses the same mode of propulsion as other rowing-propelled medusae.

One consequence of rowing propulsion is that the vortices are greater in volume and more closely spaced than vortices predicted from simple-jet models. This can result in greater fluid entrainment throughout the pulsation cycle and more efficient thrust production (Dabiri et al. 2005). These differences from conventional medusan jet production are advantageous for cruising predators who swim almost continuously and for whom greater fluid entrainment translates to greater encounter rates with prey (Costello \& Colin 1994).

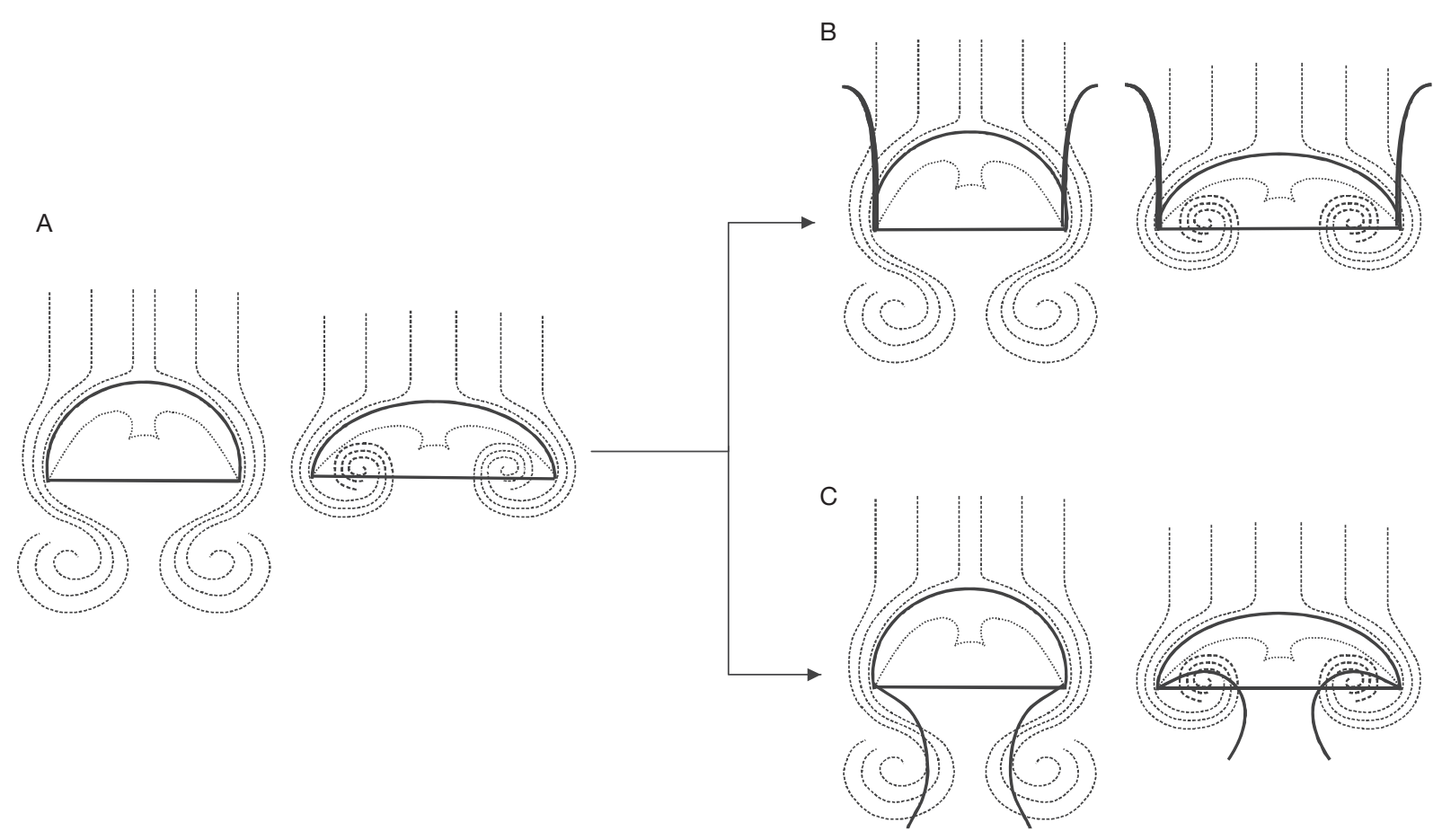

Fig. 7. Flow (dotted lines) around cruising predatory medusae with oblate-shaped bells during (A) contraction (left) and relaxation (right) phases of the swimming cycle, and of tentacle placement in flow around (B) upstream cruising foragers and (C) downstream cruising foragers. Starting vortex ring is visible during the contraction phase and the stopping vortex ring is visible during the relaxation phase. Note that the flow around both upstream and downstream cruising foragers is similar 


\section{Form and function}

The oblate bell shapes, rowing propulsion modes, and almost continuous swimming behavior suggest that Craspedacusta sowerbyi, Solmissus albescens and Nausithoë punctata (Table 2) forage as cruising predators. This is supported by in situ observations of their behavior (Milne 1938, Deacon \& Haskell 1967, Larson 1979, Mills \& Goy 1988, Larson et al. 1989, Raskoff 2002). In contrast to ambush medusan foragers, cruising medusae typically swim with their tentacles extended (Colin \& Costello 2002, Colin et al. 2003). C. sowerbyi, S. albescens and N. punctata were morphologically similar to other cruising species possessing high velar aperture ratios ( $>74 \%$ ) and low fineness ratios $(<0.4)$, as well as being larger and more oblate than ambush-foraging medusae (Fig. 8; ANOVA, $\mathrm{p}<$ 0.0001; Tukey-Kramer post hoc test, p < 0.05). Likewise, C. sowerbyi, S. albescens and $N$. punctata were behaviorally similar to other documented cruising species possessing trailing tentacles and spent a greater proportion of time swimming with tentacles extended than did ambush species (Fig. 8; species pooled within groups, $\mathrm{ANOVA}, \mathrm{df}_{\text {among }}=1, \mathrm{df}_{\text {within }}=222, \mathrm{p}<0.0001$ ) The major performance differences observed between C. sowerbyi, S. albescens and N. punctata and previously documented cruising medusae appeared to be the more proficient swimming of the 3 species with leading tentacle placement compared to those with trailing tentacles. C. sowerbyi, S. albescens and $N$. punctata accelerated more rapidly than other oblate species and $S$. albescens had greater velocities than any of the cruising species. Perhaps these differences in swimming performance are related to the migration requirements of both $C$. sowerbyi and $S$. albescens (Mills \& Goy 1988, Petrusek \& Šedivý 2005).

The swimming behavior of Craspedacusta sowerbyi, Solmissus albescens and Nausithoë punctata resembles that of cruising medusae with trailing tentacles in terms of kinematics, propulsion and the amount of time spent swimming. However do the medusae with leading tentacles feed similarly to those with trailing tentacles? For both types of medusae, swimming serves to generate flows that draw fluid past the bell of the medusae and their oblate bell kinematics create large stopping and starting vortex structures downstream of the bell during bell contraction and expansion, respectively (Fig. 7A). For species with trailing tentacles, the tentacles are positioned in regions of maximum flow (Fig. 7B; Costello \& Colin 1995, Ford et al. 1997, Colin \& Costello 2002, Dabiri et al. 2005), while for medusae with leading tentacles (such as C. sowerbyi, S. albescens and N. punctata) the tentacles are positioned in the flow around the bell (Fig. 7C), where fluid velocities and dye deformation are much lower than in regions adjacent to the bell margin and downstream (Figs. $3 \& 4$ ). In fact, the tentacles of C. sowerbyi extended into the upstream region where particle velocities were negligible during both phases of bell contraction. Presumably this aids in prey capture,

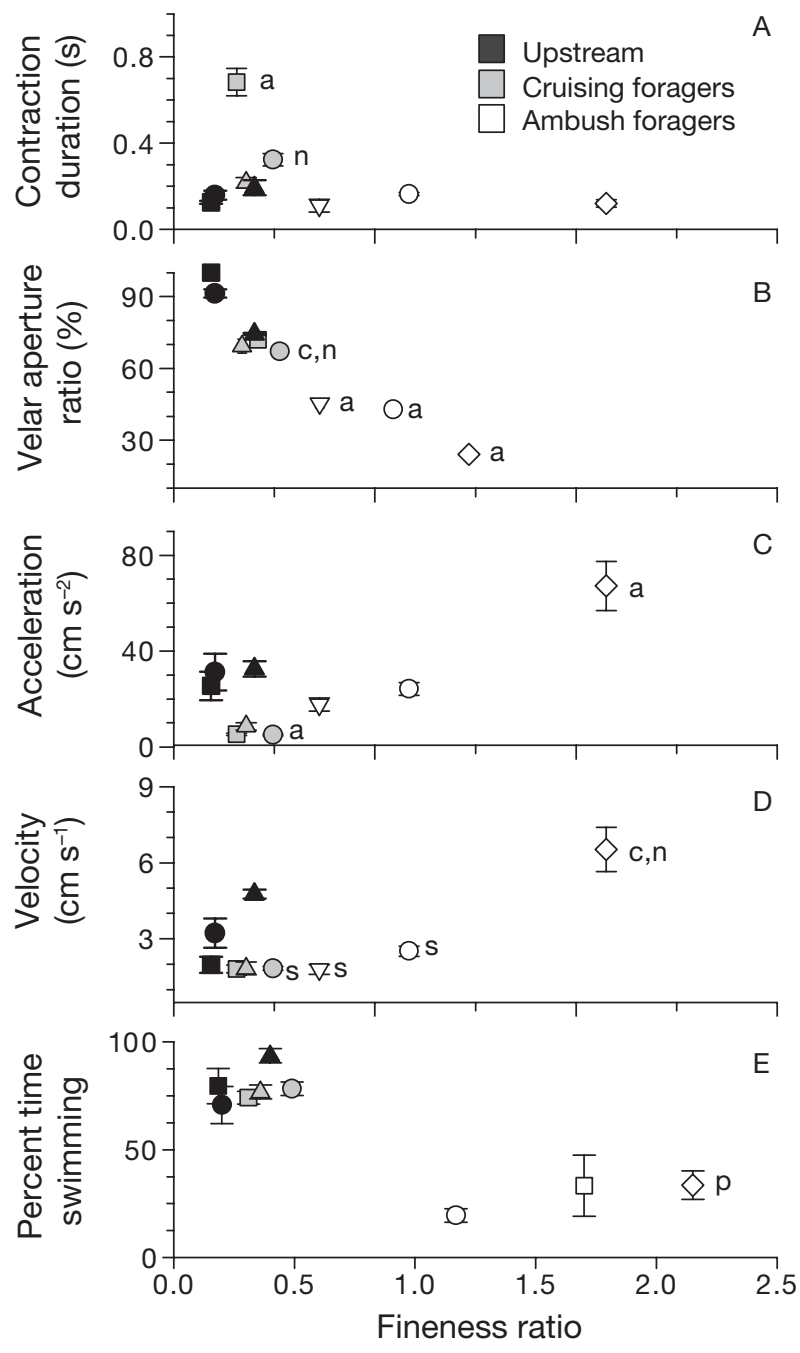

Fig. 8. Comparison of morphological and kinematic traits of upstream medusae (black symbols) to those of cruising (grey symbols) and ambush (open symbols) medusae with trailing tentacles; upstream species-(ם) Nausithoë punctata, (-) Craspedacusta sowerbyi and ( $\mathbf{\Delta}$ ) Solmissus albescens; cruising species - (ロ) Mitrocoma cellularia, (๑) Aequorea victoria and (৯) Phialidium gregarium; ambush species - $(\diamond)$ Aglantha digitale, (O) Sarsia sp., ( $\nabla)$ Proboscidactyla flavicirrata and ( $\square$ ) Leukartiara sp. Variables are plotted against fineness ratio of the medusae. Data of cruising and ambush species from Colin \& Costello (2002) and Colin et al. (2003). Error bars: standard errors. For each graph, upstream species were compared to cruising and ambush medusae by ANOVA test (where $\mathrm{df}_{\text {among }}=5$ and $\mathrm{df}_{\text {within }}=12$ for each test except for 'Percent time swimming', see 'Discussion' for details). Species within significantly different groups (ANOVA, $\mathrm{p}<0.05$ ) were compared by TukeyKramer post hoc test. Cruising and ambush species that were significantly different (Tukey-Kramer post hoc test, $p<0.05$ ) from $S$. albescens (s), C. sowerbyi (c), N. punctata (n) or all three (a) are denoted. p: significant pooled comparisons 
since C. sowerbyi (Spadinger \& Maier 1999), $S$. albescens (Mills \& Goy 1988, Larson et al. 1989, Raskoff 2002) and N. punctata (Larson 1979, present study) have been found to capture prey with their leading tentacles during swimming. Likewise, cruising medusae with trailing tentacles capture prey during swimming using their tentacles, but with the important difference that the prey are caught downstream of the swimming medusa. Previous studies have described medusae with leading tentacles foraging by 'ramming' into unsuspecting prey (Raskoff 2002). In contrast, cruising medusae with trailing tentacles entrain prey into vortices which subsequently pass through tentacles positioned downstream of the bell margin. We suggest that medusae possessing either leading and trailing tentacles function similarly in terms of propulsion and foraging modes but differ in the region of the flow around the bell from which prey are captured, i.e. upstream versus downstream, respectively (Fig. 7). That difference may be important for the trophic roles played by upstream and downstream feeding medusae.

\section{Trophic role}

Tentacle characteristics, swimming patterns and fluid flows around medusae interact to determine prey selection (Purcell 1997 and references therein) and an alteration of any of these traits may alter prey selection. Table 3 summarizes prey selection patterns of upstream foragers from previous studies. While the amount of data available on the prey selection of upstream foragers is limited, we suggest that several patterns are evident. Although upstream foragers ingest a diverse array of prey types, all the prey types ingested by upstream foragers appear to be relatively large, motile mesozooplankton that are capable of detecting and escaping predators. Rapidly swimming prey are more characteristic of ambush foragers than downstream cruising foragers (Purcell \& Mills 1988,
Purcell \& Grover 1990, Matsakis \& Conover 1991, Suchman \& Sullivan 1998, Costello \& Colin 2002). However, the ability of upstream cruising medusae to capture rapidly escaping prey may result from the unique positioning of tentacles in the flow regimes around these medusae. Fluid velocities upstream of a swimming medusae are generally laminar and of lower velocity than the turbulent, higher velocity flows downstream of the medusa's bell margin (Colin \& Costello 2002, Fig. 3 in the present study). Tentacle positioning within the low-shear upstream flow enables a medusa to approach motile prey with minimal hydrodynamic disturbance prior to prey contact. Raskoff (2002) argued that this allows upstream cruising medusae to 'ram' into unwary prey and that this mode of stealth predation by medusae may be the most frequent predatory mode of medusae occupying mid and deep oceanic regions. The ability of upstream foragers to capture prey via stealth stands in sharp contrast to downstream foragers that rely upon highly sheared currents created at the bell margin to forcibly entrain prey that are then transported to capture surfaces that trail behind the advancing bell (Costello \& Colin 1994, 1995). These flow-dominated factors act in concert with other traits, such as tentacle spacing, nematocyst type and arrangement, to influence the rate with which encounters result in captures (Purcell \& Mills 1988, Purcell 1997). Although considerable data exists describing hydrodynamic regimes and prey selection patterns of downstream cruising medusae, upstream foragers have been less well examined and further confirmation of these hypotheses is required.

\section{Evolutionary patterns}

Similar morphological traits that have arisen via homoplasy are common among the Cnidaria (Bouillon \& Boero 2000, Collins 2002, Marques \& Collins 2004) and convergence upon similar morphological traits is to be expected

Table 3. Prey most commonly ingested by different species of upstream foragers

\begin{tabular}{|llll|}
\hline Upstream species & Prey type & Method & Source \\
\hline Craspedacusta sowerbyi & Cladocerans, copepods & $\begin{array}{l}\text { Gut contents + } \\
\text { mesocosm experiments }\end{array}$ & $\begin{array}{l}\text { Dodson \& Cooper (1983) } \\
\text { Spadinger \& Maier (1999) } \\
\text { Jankowski \& Ratte (2001) } \\
\text { Jankowski et al. (2005) }\end{array}$ \\
Solmissus albescens & Siphonophores, salps, ctenophores & Gut contents & Raskoff (2002 + refs therein) \\
Nausithoë punctata & $\begin{array}{l}\text { Siphonophores, rhopalonematid } \\
\text { hydromedusae }\end{array}$ & Prey capture observations & Present study \\
Periphylla periphylla & $\begin{array}{l}\text { Copepods (specifically Calanus spp. } \\
\text { and Euchaeta spp.) }\end{array}$ & Gut content & Fosså 1992 \\
& & & Sørnes \& Aksnes (2004) \\
\hline
\end{tabular}


among animals from the same phylum that have evolved to respond to similar problems in similar niches (Moore \& Willmer 1997). Upstream foraging by the hydromedusae Craspedacusta sowerbyi, Solmissus albescens and the scyphomedusae Nausithoë punctata is such a trait that has evolved in parallel among several medusan lineages. The distant relationship among these species and the rare appearance of upstream foraging among medusae ( $<11 \%$ of species identified by Mayer 1910) makes it unlikely that $C$. sowerbyi, $S$. albescens and $N$. punctata share a common ancestor characterized by an upstream cruising mode of foraging. Most hydromedusan lineages contain either primarily jet-propelled (Anthomedusae, Siphonophorae, Trachymedusae, Laingiomedusae) or downstream, rowing-propelled (Leptomedusae, Narcomedusae) medusae. Developmental evidence indicates that the upstream, rowing-propelled state is likely to be a derived condition for hydromedusae. For example, although upstream foragers as adults, juvenile C. sowerbyi possess prolate bells with trailing tentacles and are jet-propelled (Boulenger \& Flower 1928). The incomplete nature of the medusan fossil record precludes most definitive statements concerning the evolution of medusan morphologies; however, upstream foraging by cruising medusae appears to be a convergent characteristic arrived at by several distinct medusan lineages.

\section{CONCLUSIONS}

Craspedacusta sowerbyi, Solmissus albescens and Nausithoë punctata are 3 medusan species from different medusozoan lineages that are part of a small number of extant species that have evolved the unique form of positioning their tentacles aborally during swimming (Fig. 1). In addition to similar tentacle placement, our results suggest that they also function similarly in terms of their interactions with surrounding fluids, swimming kinematics and their foraging behaviors. Based on our current understanding of the evolutionary relationships of these species, we suggest that these traits represent evolutionarily convergent traits that have enabled these cruising medusae to exploit different prey resources compared to more widespread medusan species with trailing tentacles.

Acknowledgements. We are grateful for the support of the National Science Foundation (OCE-0116236 and OCE0350834 awarded to J.H.C. and OCE-0351398 awarded to S.P.C.), the Ministry of Science and Technology of the Republic of Croatia, and the Polytechnic of Dubrovnik (Croatia). We thank M. Ford for his help with the collection and videoing of Craspedacusta sowerbyi, and R. Waggett and C. Suchman for valuable comments that improved earlier drafts of the manuscript.

\section{LITERATURE CITED}

Benović A, Lučić D, Onofri V (2000) Does change in an Adriatic hydromedusan fauna indicate an early phase of marine ecosystem destruction? PSZN I Mar Ecol 21: 221-231

Bouillon J, F Boero (2000) The hydrozoa: a new classification in the light of old knowledge. Thalassia Salentina 24: $1-296$

Boulenger MA, Flower WU (1928) The Regent's Park medusa, Craspedacusta sowerbyi, and its identity with C. (Microhydra) ryderi. Proc Zool Soc Lond 66: 1005-1015

Colin SP, Costello JH (1996) Relationship between morphology and hydrodynamics during swimming by the hydromedusae Aequorea victoria and Aglantha digitale. Sci Mar 60:35-42

Colin SP, Costello JH (2002) Morphology, swimming performance and propulsive mode of six co-occurring hydromedusae. J Exp Biol 205:427-437

Colin SP, Costello JH, Klos E (2003) In situ swimming and feeding behavior of eight co-occurring hydromedusae. Mar Ecol Prog Ser 253:305-309

Colin SP, Costello JH, Graham WM, Higgins J III (2005) Omnivory by the small cosmopolitan hydromedusa Aglaura hemistoma. Limnol Oceanogr 50:1264-1268

Collins AG (2000) Towards understanding the phylogenetic history of Hydrozoa: hypothesis testing with 18S gene sequence data. Sci Mar 64(suppl 1):5-22

Collins AG (2002) Phylogeny of Medusozoa and the evolution of cnidarian life cycles. J Evol Biol 15:418-432

Costello JH, Colin SP (1994) Morphology, fluid motion and predation by the scyphomedusa Aurelia aurita. Mar Biol 121:327-334

Costello JH, Colin SP (1995) Flow and feeding by swimming scyphomedusae. Mar Biol 124:399-406

Costello JH, Colin SP (2002) Prey resource use by coexistent hydromedusae from Friday Harbor, Washington. Limnol Oceanogr 47:934-942

Dabiri JO, Colin SP, Costello JH, Gharib M (2005) Flow patterns generated by oblate medusan jellyfish: field measurements and laboratory analyses J Exp Biol 208:1257-1265

Daniel TL (1983) Mechanics and energetics of medusan jet propulsion. Can J Zool 61:1406-1420

Deacon JE, Haskell WL (1967) Observations on the ecology of the freshwater jellyfish in Lake Mead, Nevada. Am Midl Nat 78:155-166

Dodson SI, Cooper SD (1983) Trophic relationships of the freshwater jellyfish Craspedacusta sowerbyi Lankester 1880. Limnol Oceangr 28:345-351

Ford MD, Costello JH, Klos E (1997) Swimming and feeding by the scyphomedusa Chrysaora quinquecirrha. Mar Biol 129:355-362

Fosså JH (1992) Mass occurrence of Periphylla periphylla (Scyphozoa, Coronatae) in a Norwegian fjord. Sarsia 77: $237-251$

Greene CH (1986) Patterns of prey selection: implications of predator foraging tactics. Am Nat 128:824-839

Jankowski T, Ratte HT (2001) On the influence of the freshwater jellyfish Craspedacusta sowerbii on the zooplankton community. Verh Int Ver Theor Angew Limnol 27: 3287-3290

Jankowski T, Strauss T, Ratte HT (2005) Trophic interactions of the freshwater jellyfish Craspedacusta sowerbii. J Plankton Res 27:811-823

Larson RJ (1979) Feeding in coronate medusae (class Scyphozoa, Order Coronatae). Mar Behav Physiol 6:123-129 
Larson RJ, Mills CE, Harbison GR (1989) In situ foraging and feeding behavior of narcomedusae (Cnidaria: Hydrozoa). J Mar Biol Assoc UK 69:785-794

Madin LP (1988) Feeding behavior of tentaculate predators: in situ observations and a conceptual model. Bull Mar Sci 43:413-429

Marques AC, Collins AG (2004) Cladistic analysis of Medusozoa and cnidarian evolution. Invertebr Biol 123:23-42

Matsakis S, Conover RJ (1991) Abundance and feeding of medusae and their potential impact as predators on other zooplankton in Bedford Basin (Nova Scotia, Canada) during spring. Can J Fish Aquat Sci 48:1419-1430

Mayer AG (1910) Medusae of the world. Carnegie Institution of Washington, Washington, DC

Mills CE, Goy J (1988) In situ observations of the behavior of mesopelagic Solmissus narcomedusae (Cnidaria, Hydrozoa). Bull Mar Sci 43:739-751

Milne LJ (1938) Some aspects of the behavior of the freshwater jellyfish, Craspedacusta sp. Am Nat 72:462-472

Moore J, Willmer P (1997) Convergent evolution in invertebrates. Biol Rev 72:1-60

Petrusek A, Šedivý J (2005) Vertical migrations of the freshwater jellyfish Craspedacusta sowerbyi in stratified water bodies. ASLO Aquatic Sciences Meeting, Salt Lake City, UT. Abstract book p 84

Purcell JE (1989) Predation on fish larvae and eggs by the hydromedusa (Aequorea victoria) at a herring spawning ground in British Columbia. Can J Fish Aquat Sci 46: $1415-1427$

Purcell JE (1997) Pelagic cnidarians and ctenophores as predators: selective predation, feeding rates, and effects on prey populations. Ann Inst Océanogr 73:125-137

Editorial responsibility: Howard Browman (Associate Editorin-Chief), Storebø, Norway
Purcell JE, Mills CE (1988) The correlation between nematocyst types and diets in pelagic hydrozoa. In: Hessinger DA, Lenhoff HM (eds) The biology of nematocysts. Academic Press, New York, p 463-485

Purcell JE, Grover JJ (1990) Predation and food limitation as causes of mortality in larval herring at a spawning ground in British Columbia. Mar Ecol Prog Ser 59:55-61

Purcell JE, Nemazie DA (1992) Quantitative feeding ecology of the hydromedusan Nemopsis bachei in Chesapeake Bay. Mar Biol 113:305-311

Raskoff KA (2002) Foraging, prey capture, and gut contents of the mesopelagic narcomedusae Solmissus spp. (Cnidaria: Hydrozoa). Mar Biol 141:1099-1107

Sørnes TA, Aksnes DL (2004) Predation efficiency in visual and tactile zooplanktivores. Limnol Oceanogr 49: $69-75$

Spadinger R, Maier G (1999) Prey selection and diel feeding of the freshwater jellyfish, Craspedacusta sowerbyi. Freshw Biol 41:567-573

Suchman CL, Sullivan BK (1998) Vulnerability of the copepod Acartia tonsa to predation by the scyphomedusa, Chrysaora quinquecirrha. Mar Biol 132:237-245

Sullivan BK, Garcia JR, MacPhee GK (1994) Prey selection by the scyphomedusan predator Aurelia aurita. Mar Biol 121: 335-341

Valentine JW (2004) On the origin of phyla. Chicago University Press, Chicago

Weihs D (1977) Periodic jet propulsion of aquatic creatures. Fortschr Zool 24:171-175

Willmer (2003) Convergence and homoplasy in the evolution of organismal form. In: Muller GB, Newman SA (eds) Origination of organismal form. MIT Press, Cambridge, MA, p 33-49

Submitted: November 21, 2005; Accepted: May 1, 2006

Proofs received from author(s): November 20, 2006 